\title{
Surface Orientation Dependent Water Dissociation on Rutile Ruthenium Dioxide
}

Rao, Reshma R.; Kolb, Manuel J.; Hwang, Jonathan; Pedersen, Anders; Mehta, Apurva; You, Hoydoo; Stoerzinger, Kelsey A.; Feng, Zhenxing; Zhou, Hua; Bluhm, Hendrik

Total number of authors:

13

Published in:

Journal of Physical Chemistry C

Link to article, DOI:

10.1021/acs.jpcc.8b04284

Publication date:

2018

Document Version

Peer reviewed version

Link back to DTU Orbit

Citation (APA):

Rao, R. R., Kolb, M. J., Hwang, J., Pedersen, A., Mehta, A., You, H., Stoerzinger, K. A., Feng, Z., Zhou, H., Bluhm, H., Giordano, L., Stephens, I. E. L., \& Shao-Horn, Y. (2018). Surface Orientation Dependent Water Dissociation on Rutile Ruthenium Dioxide. Journal of Physical Chemistry C, 122(31), 17802-17811. https://doi.org/10.1021/acs.jpcc.8b04284

\section{General rights}

Copyright and moral rights for the publications made accessible in the public portal are retained by the authors and/or other copyright owners and it is a condition of accessing publications that users recognise and abide by the legal requirements associated with these rights.

- Users may download and print one copy of any publication from the public portal for the purpose of private study or research.

- You may not further distribute the material or use it for any profit-making activity or commercial gain

- You may freely distribute the URL identifying the publication in the public portal 


\section{Surface Orientation Dependent Water Dissociation on Rutile Ruthenium Dioxide}

Reshma R Rao ${ }^{1 * \#}$, Manuel J Kolb ${ }^{2 \dagger \#}$, Jonathan Hwang ${ }^{3}$, Anders Filsøe Pedersen ${ }^{4}$, Apurva Mehta $^{5}$, Hoydoo You ${ }^{6}$, Kelsey A Stoerzinger ${ }^{3 \ddagger}$, Zhenxing Feng ${ }^{7}$, Hua Zhou ${ }^{8}$, Hendrik Bluhm $^{9}$, Livia Giordano ${ }^{1,10}$, Ifan E L Stephens ${ }^{4 \S}$, Yang Shao-Horn ${ }^{1,2,3^{*}}$

${ }^{\#}$ Contributed equally

${ }^{1}$ Department of Mechanical Engineering, Massachusetts Institute of Technology, Cambridge, Massachusetts 02139, United States

${ }^{2}$ Research Laboratory of Electronics, Massachusetts Institute of Technology, Cambridge, Massachusetts 02139, United States

${ }^{3}$ Department of Materials Science and Engineering, Massachusetts Institute of Technology, Cambridge, Massachusetts 02139, United States

${ }^{4}$ Section for Surface Physics and Catalysis, Department of Physics, Technical University of Denmark, 2800 Kgs. Lyngby, Denmark

${ }^{5}$ SLAC National Accelerator Laboratory, Menlo Park, CA 94025, United States

${ }^{6}$ Materials Science Division, Argonne National Laboratory, Argonne, Illinois 60439, United States

${ }^{7}$ School of Chemical, Biological, and Environmental Engineering, Oregon State University, Corvallis, OR 97331, United States

${ }^{8}$ X-ray Science Division, Argonne National Laboratory, Argonne, IL 60439, United States

${ }^{9}$ Chemical Sciences Division, Lawrence Berkeley National Laboratory, Berkeley, California 94720, United States

${ }^{10}$ Dipartimento di Scienza dei Materiali, Università di Milano-Bicocca, Milano, Italy 
${ }^{\dagger}$ Current address: FYSIKUM, AlbaNova, Stockholm University, S-10691 Stockholm, Sweden and SUNCAT Center for Interface Science and Catalysis, Department of Chemical Engineering, Stanford University, 443 Via Ortega, Stanford, California 94305, United States

‡ Current address: Physical and Computational Sciences Directorate, Pacific Northwest National Laboratory, Richland Washington 99354, United States

${ }^{\S}$ Current address: Royal School of Mines, Imperial College London, South Kensington Campus, London, SW 2AZ, United Kingdom

\section{AUTHOR INFORMATION}

\section{Corresponding Authors}

* Reshma R Rao (reshmar@mit.edu)

* Yang Shao-Horn (shaohorn@mit.edu) 


\section{ABSTRACT}

Rutile $\mathrm{RuO}_{2}$ is a highly active catalyst for a number of (electro)chemical reactions in aqueous solutions or in humid environments. However, the study of the interaction of $\mathrm{RuO}_{2}$ surfaces with water has been confined largely to the ultra-high vacuum environment, and to the thermodynamically stable (110) surface. In this work, we combine ambient pressure X-ray photoelectron spectroscopy, in situ surface diffraction and density functional theory calculations to investigate how four different facets of $\mathrm{RuO}_{2}$ interact with water under humid and electrochemical environments. The vacant coordinatively unsaturated Ru site (CUS) allows for the adsorption and dissociation of water molecules. Different surfaces exhibit unique binding energetics for $-\mathrm{H}_{2} \mathrm{O}$ and $-\mathrm{OH}$ and can allow for different degrees of hydrogen bonding between the adsorbates. Consequently, the degree of water dissociation is found to be sensitive to the surface crystallographic orientation - being maximum for the (101) surface, followed by the (110), (001) and (100) surfaces. This study identifies crystallographic orientation as an important parameter to tune not only the density of active sites but also the energetics for water dissociation; this finding is of great significance for many catalytic reactions, where water is a key reactant, or product. 


\section{TEXT}

\section{Introduction}

Water is an important environmental molecule; it can serve either as a reactant, product, promoter or inhibitor for several different (electro)catalytic reactions on surfaces ${ }^{1-6}$. In particular, the interaction of water with rutile ruthenium dioxide surfaces is critical to understanding its unparalleled catalytic activity for a number of gas phase and (electro)catalytic reactions ${ }^{7}$. Under aqueous conditions, $\mathrm{RuO}_{2}$ exhibits state-of-the-art activity for the oxygen evolution reaction ${ }^{8-13}$, whose slow kinetics underpins the low efficiencies of renewable hydrogen production ${ }^{14-21}$. In addition, it serves as dimensionally stable anodes in chlor-alkali electrolysis, which is one of the largest industrial electrochemical processes ${ }^{22-24}$. It has also been used as a model system to study gas phase reactions, such as $\mathrm{CO}$ oxidation ${ }^{25-28}, \mathrm{NH}_{3}$ oxidation ${ }^{29}, \mathrm{CH}_{3} \mathrm{OH}$ oxidation ${ }^{30}, \mathrm{HCl}$ oxidation $^{31,32}$ and NO oxidation reactions ${ }^{33}$. Notably, $\mathrm{RuO}_{2}$ surfaces have shown high CO oxidation rates at low temperatures, in realistic humid atmospheres, where other metal oxides suffer from anodic corrosion ${ }^{34,35}$.

The unique interaction of water with $\mathrm{RuO}_{2}$ surfaces has been a subject of intense investigation, both theoretically ${ }^{36-39}$ and experimentally ${ }^{40-41}$, with most studies being focused on the thermodynamically stable (110) facet. The (110) facet exposes two unique Ru sites, namely a coordinatively unsaturated site, CUS, bound to five oxygen atoms and a bridge site bound to six oxygen atoms ${ }^{7}$. Dosing gas molecules, such as $\mathrm{O}_{2}{ }^{26-28,30,42,43}$, $\mathrm{CO}^{25-28}$ and $\mathrm{NH}_{3}{ }^{29}$ resulted in their adsorption at the CUS site, which has been deemed as the active site for small molecule oxidation. Water on the other hand, has been shown to interact in different ways with rutile surfaces - it can adsorb directly as molecular water on 
the CUS site ${ }^{40}$, it can dissociate at the CUS site to form an $-\mathrm{OH}$ group ${ }^{44,45}$, or it can dissociate on bridging oxygen vacancies ${ }^{46-47}$, with the nature of the interaction being dependent on the defect density, water and oxygen chemical potential. Theoretical and experimental studies on $\mathrm{RuO}_{2}{ }^{41,48}$, and other oxides such as $\mathrm{MgO}^{49,50}, \mathrm{ZnO}^{51,52}$ and $\mathrm{Fe}_{3} \mathrm{O}_{4}{ }^{53}$ suggest that lateral interactions between adsorbates $\left(-\mathrm{H}_{2} \mathrm{O},-\mathrm{OH}\right)$ can stabilize structures where not every water molecule is dissociated, forming an ordered superstructure .

Previous studies have been limited to the ultra-high vacuum (UHV) environment and the (110) facet, with the applicability to high humidity environments, aqueous solutions and different crystallographic facets being unknown. While for the (110) surface, the CUS Ru atoms and the surface $\mathrm{Ru}$ atoms bonded to the bridging oxygen atoms are distinct ${ }^{25}$, the CUS Ru atom on the (100), (001) and (101) surfaces are also coordinated to surface bridging oxygen atoms ${ }^{54-55}$. In addition, for the (001) stoichiometric surface, the Ru surface atoms are only 4 fold coordinated, with the ability to form two additional bonds with reactant molecules ${ }^{56}$. Pseudo-valence charge density contour plots of the (110) and (100) surface have revealed that the change of crystallographic orientation results in a change in hybridization of CUS Ru atoms, which can impact activity and selectivity for a number of different reactions ${ }^{54}$. Previous DFT calculations on these two surfaces have suggested that this also leads to the difference in CO binding strength on the two surfaces, with the (110) surface binding CO more strongly $(1.2 \mathrm{eV})$ as compared to the $(100)$ surface $(0.7 \mathrm{eV})^{54}$. Furthermore, geometric arrangement of CUS sites and bridging oxygen sites that adsorb $\mathrm{OH}$ and $-\mathrm{H}$ respectively in the water dissociation process also have had a considerable impact on water activation for isostructural $\mathrm{TiO}_{2}$ surfaces, where the (100) surface was shown to be more active than the (110) termination ${ }^{57}$. Thus, although crystallographic 
orientation has shown to play an important role in the activation of small molecules on rutile oxide surfaces, the influence of surface structure on water dissociation ability on rutile $\mathrm{RuO}_{2}$ remains unknown. The influence of the presence of bulk water on the energetics of water dissociation is also questionable. Recent studies on strained $\mathrm{SrIrO}_{3}$ films suggest that while good correlation is observed between oxygen binding energetics and DFT in the gas phase environment (measured using APXPS), no influence on oxygen electroadsorption was observed in aqueous solution (measured by shifts in redox peaks observed in cyclic voltammograms) $)^{58}$.

Herein, we study the impact of surface structure on the dissociative tendency of water on oriented rutile surfaces of $\mathrm{RuO}_{2}$. Four different orientations were studied - (110), (100), (101) and (001). First, ambient pressure X-ray photoelectron spectroscopy was used to study the chemical speciation on these oxide surfaces in water vapor atmospheres ranging from 0.01 mTorr to 1 Torr. The surface structural changes under electrochemical conditions and a well-defined oxygen chemical potential were studied using surface X-ray scattering, or crystal truncation rod analysis. Finally, density functional theory calculations were used to theoretically investigate the water dissociation tendency as a function of crystallographic orientation. Through the combination of these unique in situ probes with ab initio theory, our work provides the first molecular-level insight into orientationdependent water dissociation on rutile $\mathrm{RuO}_{2}$ surfaces. We find that the (101) orientation tends to adsorb water dissociatively, both under UHV and aqueous conditions, while other facets, such as the (100), result in molecular adsorption at higher water pressures. Their interaction with water is very different from the (110) surface where water only partially 
dissociates. This study highlights the role of crystallographic termination as an additional lever to tune water dissociation ability on oxide surfaces.

\section{Methods}

\subsection{Sample Preparation}

Epitaxial thin films were grown using PLD. The (110), (100), (101) and (001) films were grown on (001)-oriented $\mathrm{MgO}$, (001)-oriented $\mathrm{SrTiO}_{3}$, (101)-oriented $\mathrm{TiO}_{2}$ and (001)oriented $\mathrm{TiO}_{2}$ substrates (form CrysTec and MTI) respectively from a polycrystalline $\mathrm{RuO}_{2}$ target. In order to obtain an atomically flat surface, the $\mathrm{SrTiO}_{3}$ substrates were treated with $\mathrm{NH}_{4} \mathrm{~F}$-buffered $\mathrm{HF}$ and annealed at $950^{\circ} \mathrm{C}$ in an oxygen atmosphere for 1 hour, while the $\mathrm{MgO}$ and $\mathrm{TiO}_{2}$ subsbtrates were not pre-treated but annealed at growth temperature for 30 minutes. PLD deposition was carried out using a $\mathrm{KrF}$ excimer laser $(\lambda=248 \mathrm{~nm})$. Films of $\sim 25 \mathrm{~nm}$ thickness were deposited at an oxygen pressure of 50 mTorr and cooled to room temperature under 200 Torr oxygen. X-ray diffraction measurements were performed using a four-circle diffractometer (X'Pert PRO, PANalytical) in normal and off-normal configurations and the morphology of the film surface was measured using atomic force microscopy (Bruker Dimension Icon).

Oriented single crystals of the (110), (100) and (101) orientation were obtained using an oxidative evaporation/redeposition method described elsewhere in references 59, 60. The (001) crystal was obtained by cutting and polishing a (110) crystal in the (001) normal direction. Electrical contacts were applied to the back of the crystals and the crystals were 
mounted in a Teflon mould (FEP 100, DuPont, Wilmington, DE) with the desired orientation exposed to the electrolyte.

\subsection{Electrochemistry}

Electrochemical measurements were performed using a Biologic SP-300 potentiostat in a standard three-electrode setup. $120 \mathrm{~mL}$ of $0.1 \mathrm{M} \mathrm{HClO}_{4}\left(70 \%\right.$ Veritas ${ }^{\circledR}$ double distilled) was prepared using deionized water (Millipore, $>18.2 \mathrm{M} \Omega \mathrm{cm}$ ). The reference electrode used was a $4 \mathrm{M}$ saturated Ag/AgCl electrode (Pine), which was calibrated to the RHE scale. A large surface area Pt electrode was used as the counter electrode. For each measurement, fresh electrolyte was prepared and pre-saturated with Ar for 60 minutes, and Ar was also left bubbling while measuring to prevent oxygen reduction at low potentials. Cyclic voltammetry measurements were performed at $50 \mathrm{mV} / \mathrm{s}$ and electrical impedance spectroscopy measurements were conducted at open circuit potential with an amplitude of $10 \mathrm{mV}$. The potentials reported versus RHE are corrected for the electrolyte/cell resistance $(\sim 50 \Omega)$ measured using the high frequency intercept of the real resistance obtained from the Nyquist plot as well as the $\mathrm{pH}$ of $0.1 \mathrm{M} \mathrm{HClO}_{4}$ electrolyte measured using a pH meter. The electronic resistance between the single crystal surface and the wire is $<5 \Omega$.

\subsection{Ambient Pressure XPS}

APXPS measurements were collected at Beamline 11.0.2 at Lawrence Berkeley National Laboratory’s (LBNL) Advanced Light Source (ALS). The films were placed onto a ceramic heater and a thermocouple was mounted directly on the sample surface to probe the temperature. The O1s spectra at a given photon energy were calibrated by fixing the 
$\mathrm{Ru} 3 \mathrm{~d}_{5 / 2}$ to a binding energy of $280.7 \mathrm{eV}$ at the same photon energy. To ensure that the interaction with water is not affected by ionizing radiation, the $\mathrm{O} 1$ s spectra was measured at intervals of 1 hour at the same spot to ensure the spectra remain unchanged (Figure S11).

The samples were cleaned by heating to a temperature of $250^{\circ} \mathrm{C}$ in an oxygen pressure of 100 mTorr, until the surface carbon species were removed. Following this, the sample was cooled down to room temperature and the chamber was evacuated to a pressure $<1.5^{*} 10^{-}$ ${ }^{7}$ Torr. Water was introduced into the chamber and measurements were made at $\mathrm{p}\left(\mathrm{H}_{2} \mathrm{O}\right)=$ 0.01 mTorr, 5 mTorr, 50 mTorr, 100 mTorr, 250 mTorr and 1000 mTorr (1 Torr = 133.32 Pa). The $\mathrm{H}_{2} \mathrm{O}$ was prepared from deionized water (Millipore, $>18.2 \mathrm{M} \Omega \mathrm{cm}$ ) and was subjected to several freeze-pump-thaw cycles to degass it. At defined experimental conditions, the $\mathrm{O} 1 \mathrm{~s}$ was measured $735 \mathrm{eV}, 935 \mathrm{eV}$ and $1135 \mathrm{eV}$ incident photon energy, in order to distinguish the surface oxygen species from the bulk oxygen species (Figure S7). $\mathrm{C} 1 \mathrm{~s} /$ Ru3d measurements were made at photon energy of $490 \mathrm{eV}$ and $735 \mathrm{eV}$. The valence band and survey spectra were also collected at $490 \mathrm{eV}$ and $735 \mathrm{eV}$. For the (110) surface, an additional measurement was conducted wherein a clean sample was heated from room temperature to $200^{\circ} \mathrm{C}$ in the presence of $100 \mathrm{mTorr}$ water. The C1s/Ru3d and O1s spectra at a photon energy of $735 \mathrm{eV}$ were measured every $25^{\circ} \mathrm{C}$, with the full set of scans measured every $100^{\circ} \mathrm{C}$.

\subsection{Crystal Truncation Rod Analysis}

Surface diffraction measurements were carried out at Beamline 12 ID-D of the Advanced Photon Source. Specular and off-specular rods were collected using the reflection geometry for each surface at $0.5 \mathrm{~V}_{\mathrm{RHE}}$ and $1.0 \mathrm{~V}_{\mathrm{RHE}}$. An incident photon energy of $20 \mathrm{keV}$ was used. 
An X-ray transparent Kapton foil $(100 \mu \mathrm{m})$ was used to seal the cell, and care was taken to trap only a thin layer of electrolyte between the single crystal surface and the membrane to avoid large background signals from the electrolyte. In order to do this effectively, air from the cell was sucked out using a syringe to create a vacuum in the cell. Following this, electrolyte was injected through another syringe to form a thin layer above the crystal surface, due to capillary forces. $0.1 \mathrm{M} \mathrm{HClO}_{4}\left(70 \%\right.$ Veritas ${ }^{\circledR}$ double distilled) solution was prepared using deionized water (Millipore, $>18.2 \mathrm{M} \Omega \mathrm{cm}$ ). A saturated $\mathrm{Ag} / \mathrm{AgCl}$ electrode was used as the reference (BAS, West Lafayette, IN) and a Pt counter electrode was used.

The assembled cell was mounted on a Huber five-circle (3S+2D) diffractometer. Initial sample alignment was performed using a laser beam to ensure that the sample surface normal was at a right angle to the main axis of the diffractometer. Specular rods were recorded using a configuration with the incidence angle $=$ exit angle. For the off specular rods, the incidence angle was fixed at either $2^{\circ}$ or $4^{\circ}$. An orientation matrix was calculated to relate the motor angles to the Miller indices (hkl) for the dry sample. The intensities were measured using a pixel photon-counting area detector (PILATUS 100K model). The measured intensities were extracted by integrating the photon counts of the pixels in the region of interest on the detector and were corrected for background noise, illuminated sample surface area, electrolyte thickness and a Lorentz factor that takes into consideration the experimental geometry.

For each surface, a model was created in GenX as shown in Figure S17, S18, S22, S23, S27, S28. At each potential, 200-300 symmetrically independent data points were used for the fitting. Higher order reflections, such as (30L) and (50L) were not measured since the measured intensity at the anti-Bragg position was too weak to collect statistically 
significant data. Details of the initial positions for each surface and the constraints are listed in Table S3-S17. The Figure of Merit to be minimized was:

$$
F O M_{\log R 1}=\frac{\sum_{i}\left|\log \left(\sqrt{Y_{i}}\right)-\log \left(\sqrt{S_{i}}\right)\right|}{\sum_{i}\left|\log \left(\sqrt{Y_{i}}\right)\right|}
$$

where $Y_{i}$ is the experimentally measured intensity for point $\mathrm{i}$ and $\mathrm{S}_{\mathrm{i}}$ is the simulated intensity. All rods were fitted simultaneously, and a value $<0.10$ was obtained for all conditions, signifying a reasonably good fit. Uncertainties in the bond lengths were obtained by running the simulation ten different times with different initial conditions. The four best simulation results were used to compute the average atomic positions and their standard deviations, following the method described in reference 61. The reported error bars thus represent the robustness of the fitted structure, with the available data.

\subsection{Computational Methods}

The VASP package ${ }^{62-63}$ using the PBE functional ${ }^{64}$ and PAW projectors ${ }^{65,66}$ was used for the DFT calculations. The super cell used for each orientation was a 1x2 replication, with the replication being performed along the short axis of the cell. This allowed for symmetry breaking and adsorbate-adsorbate interactions. A cut-off energy of $500 \mathrm{eV}$ was chosen and a 6x6x1 Monkhorst-Pack k-point sampling ${ }^{67}$ was used for the super cell. The Gibbs Free Energies were calculated by correcting the DFT obtained energies for the ZPE and vibrational entropy ${ }^{68}$. The contributions of all atoms beyond the fully reduced surface were considered for the ZPE and vibrational entropy contributions. The adsorbed species were referenced to tabulated values ${ }^{69}$ of gas-phase hydrogen and water at the gas-liquid interface at 0.035 bar and $300 \mathrm{~K}$ respectively. The Computational Hydrogen Electrode, described by 
Nørskov has been used to represent the data on the RHE scale ${ }^{70}$. The gas-phase $\mathrm{O}_{2}$ reference was calculated via the formation energy of water from experimental data to avoid the inaccuracy of DFT-GGA-level $\mathrm{O}_{2}$ calculations ${ }^{71,72}$ :

$$
0.5 \mathrm{G}_{\mathrm{O}_{2}(\mathrm{~g})}=\mathrm{G}_{\mathrm{H}_{2} \mathrm{O}(\mathrm{g})}-\mathrm{G}_{\mathrm{H}_{2}(\mathrm{~g})}-\Delta \mathrm{G}_{\mathrm{H} 2 \mathrm{O} \text { form,exp }}
$$

where $\Delta \mathrm{G}_{\mathrm{H} 2 \mathrm{O} \text { form,exp }}=-2.37 \mathrm{eV}$ at a pressure of $1 \mathrm{~atm}$ and a temperature of $298.15 \mathrm{~K}$.

\section{Results and discussion}

\subsection{Molecular versus dissociative adsorption of water vapor}

We first examine the reactivity of gas phase water vapor with oriented $\mathrm{RuO}_{2}$ thin films (Figure S1 and S2). The thin film surfaces were cleaned in situ at $250{ }^{\circ} \mathrm{C}$ in an oxygen atmosphere $\left(\mathrm{pO}_{2}=100 \mathrm{mTorr}\right)$ to remove any carbon contamination on the surface (Figure S3 and S4). Water isotherm measurements were performed at $25{ }^{\circ} \mathrm{C}$ from a relative humidity of $4.2 * 10^{-5} \%\left(\mathrm{pH}_{2} \mathrm{O}=0.01 \mathrm{mTorr}\right)$ to $4.2 \%\left(\mathrm{pH}_{2} \mathrm{O}=1000\right.$ mTorr $)$. With increasing water vapor pressure, different oxygen species form, distinguishable based on their binding energies in the Oxygen 1s (O1s) spectra ${ }^{73}$. The lowest binding energy peak at $\sim 529.2 \mathrm{eV}$ is characteristic of oxygen from the oxide lattice ${ }^{74,75}$. Relative to the lattice oxygen peak, an additional peak at $~ 1.5 \mathrm{eV}$ higher binding energy grows with increasing water vapor pressure; this peak has been previously assigned to protonated bridging oxygen species. ${ }^{73,76,77}$. In concomitance with this feature, another peak appears at relatively higher binding energies, i.e. at $\sim 3.2 \mathrm{eV}$ above the binding energy of lattice oxygen, which has been assigned previously to molecularly adsorbed water, or -OH adsorbed on the CUS site, with the distinction between the two adsorbates being within the energy resolution of the

technique $^{76,77}$. We note that we find no evidence of the adsorption of carbon-related species 
upon water dosing from the C1s spectra (Figure S8). This is in accordance with surface science studies probing the interaction of $\mathrm{CO}_{2}$ with $\mathrm{RuO}_{2}$ (110) surfaces, which suggest that carbonates are not stable at room temperature ${ }^{78}$.

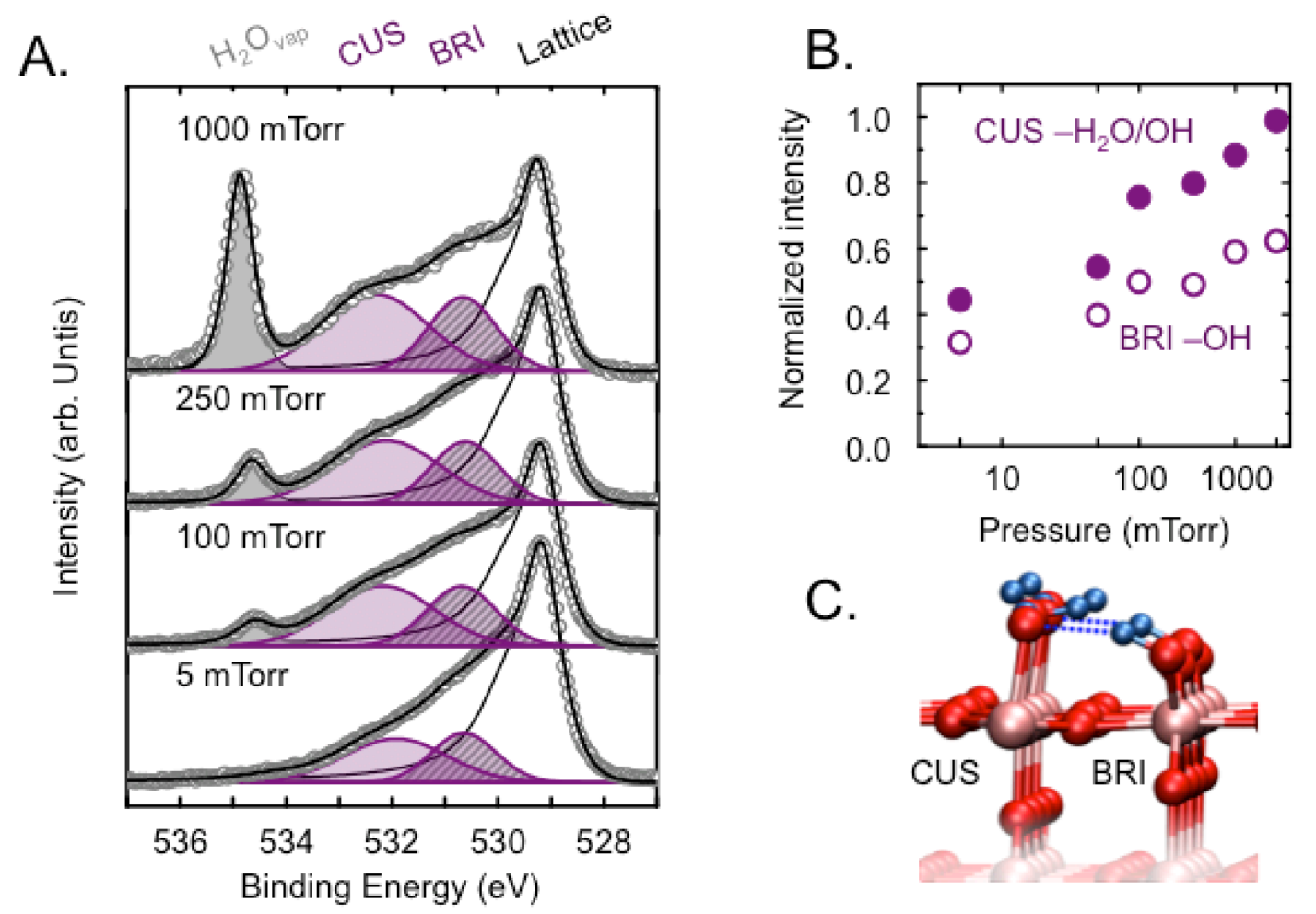

Figure 1: (A) Water isotherm at room temperature $\left(\sim 25^{\circ} \mathrm{C}\right)$ for the $\mathrm{RuO}_{2}(110)$ termination, probing the O1s core level at $735 \mathrm{eV}$ incident energy. Spectra are offset for clarity. Spectra are deconvoluted into gas phase water $\left(\mathrm{H}_{2} \mathrm{O}_{\text {vap }}\right)$ shaded in grey, $\mathrm{H}_{2} \mathrm{O}$ and $-\mathrm{OH}$ adsorbed on the CUS site shaded in purple, protonated bridging oxygen in hatched purple and lattice oxygen outlined in black. (B) Intensity of the protonated species on the CUS, either $-\mathrm{OH}$ or $-\mathrm{H}_{2} \mathrm{O}$ (filled) and bridge site (open) normalized to the lattice oxygen peak as a function of water pressure at room temperature. (C) Proposed surface structure at high water pressure showing every second water molecule on the CUS site being dissociated, with the hydrogen donated to the neighboring bridging oxygen (Top view shown in Figure S33).

Upon exposing a clean stoichiometric (110) surface to low partial pressures of water vapor ( $<100$ mTorr), the peak intensities of the protonated species on the bridge and CUS sites normalized to the lattice oxygen peak are equal, indicative of dissociative adsorption of water. This behavior is contrary to that observed at high water partial pressures, wherein the intensity contribution from the protonated species on the CUS site $\left(-\mathrm{OH}\right.$ or $\left.-\mathrm{H}_{2} \mathrm{O}\right)$ 
grows more rapidly than that from the protonated bridging oxygen species, as seen in Figure 1A and 1B. This implies that with increasing coverage of water-related species on the surface, there is a tendency for water to both adsorb molecularly as well as dissociatively. Our recent work ${ }^{79}$ on $\mathrm{RuO}_{2}(110)$ surfaces under electrochemical conditions, revealed that at 1.0 $\mathrm{V}_{\mathrm{RHE}}$, the most stable interaction of water with the (110) surface involved the dissociation of every second water molecule to form $-\mathrm{OH} / \mathrm{H}_{2} \mathrm{O}$ on the CUS site and $-\mathrm{OH} / \mathrm{O}$ on the bridge Ru site as shown in Figure 1C and Figure S33. Such findings are also consistent with high-resolution STM data ${ }^{41,48}$ and also corresponds to the two computationally energetically degenerate structures predicted by Reuter et al at high water pressure $\left(\mathrm{H}_{2} \mathrm{O}_{\text {CUS }} / \mathrm{O}_{\text {BRI }} \text { and } \mathrm{OH}_{\text {CUS }} / \mathrm{OH}_{\text {BRI }}\right)^{36}$.

Changing the surface orientation from the (110) to the (100), (101) and (001) increases the density of Rucus-O bonds on the surface from $5 / \mathrm{nm}^{2}$ to $7 / \mathrm{nm}^{2}, 8 / \mathrm{nm}^{2}$ and $10 / \mathrm{nm}^{2}$ respectively $y^{10,80,81}$. However, the differences between the interaction of water with these surfaces cannot only be accounted for by changes in the density of the surface sites. Figure 2A (and Figure S9) compares the O1s spectra of the four different orientations at room temperature in a partial pressure of water vapor of 250 mTorr. It is evident that the (101) surface has the largest propensity to dissociatively adsorb water, with an equal contribution from bridging $-\mathrm{OH}$ groups and protonated species on the CUS site, suggesting that majority of the water dissociates to form -OH on the CUS site, with the hydrogen being transferred to the bridging oxygen. This deviates from the (100) surface, where at high pressure, the intensity of the peak corresponding to the protonated CUS oxygen species increases drastically, with minimal increase in protonated bridging species (Figure 2B). This suggests a largely molecular adsorption of water at high partial pressures. Shifts in 
the gas phase peak relative to the lattice oxygen peak, used to probe changes in work function $^{82}$ or formation of a surface dipole due to the formation of surface adsorbates, such as $-\mathrm{OH}^{83,84}$ (Figure $\mathrm{S13}, \mathrm{S14}$ ) also show that the offset is largest for the (101) facet, followed by the (110), (001) and (100) (Figure S14).
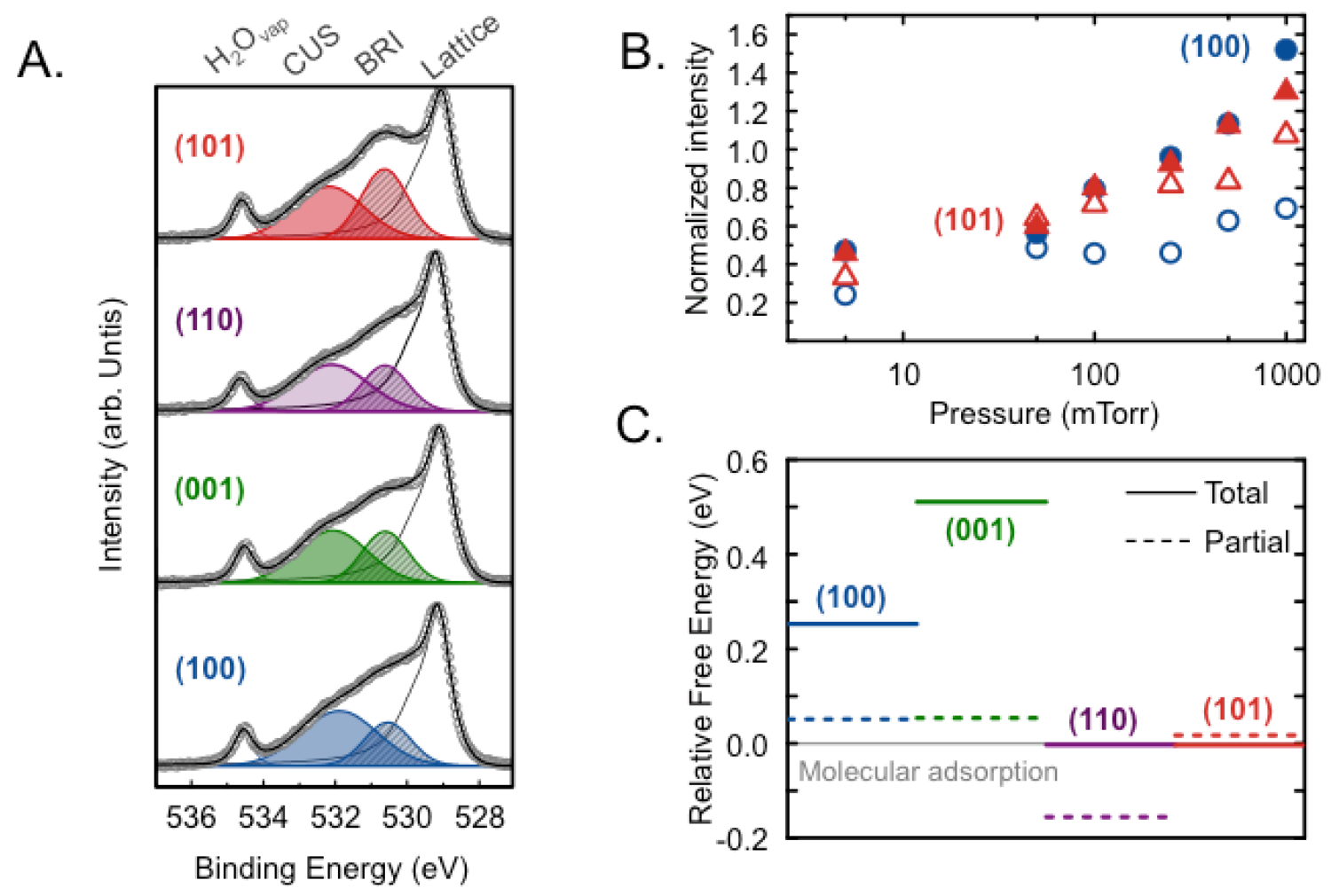

Figure 2: (A) Comparison of the $\mathrm{O} 1 \mathrm{~s}$ spectra measured at a photon energy of $735 \mathrm{eV}$ for the noted orientations. Spectra were measured at room temperature $\left(\sim 25^{\circ} \mathrm{C}\right)$ and a water vapor pressure of 250 mTorr. Spectra are offset for clarity and have been decomposed into the following components - gas phase water outlined in color, protonated species on the CUS site shaded in the corresponding color, protonated species on the BRI site hatched in the same color and lattice oxygen outlined in grey. (B) Intensity of the protonated species on the CUS (filled) and bridge site (open) normalized to the lattice oxygen peak as a function of water pressure at room temperature for the (101) surface (in red) and the (100) surface (in blue). At low partial pressures ( $<50 \mathrm{mTorr}$ ), both orientations adsorb water dissociatively, while at high partial pressures, the (101) surface preferentially adsorbs water dissociatively compared to the (100) surface. (C) Computationally calculated free energy for total (in solid lines) and partially dissociated water (in dashed line) configurations on the stoichiometric surface, for the four different surfaces. The free energy for the two conditions have been referenced to the corresponding stoichiometric surface with a full coverage of water adsorbed on the CUS site, which is shown as a solid grey line at a free energy of $0 \mathrm{eV}$. 
In order to verify these experimental observations, DFT calculations were performed to study the energetic preference of the adsorbate configurations at high water partial pressures for the different oriented surfaces, as shown in Figure 2C. For each surface, a comparison was drawn between the energetics of a fully dissociated water configuration, where each water molecule dissociates to form $-\mathrm{OH}$ on the CUS and -OH on the bridge site and a partially dissociated water configuration where only every second water molecule was deprotonated to form $-\mathrm{H}_{2} \mathrm{O} / \mathrm{OH}$ on the CUS and $-\mathrm{O} / \mathrm{OH}$ on the bridge site (Figure S32). The energetics of these structures was referenced to the configuration where water does not dissociate on the surface, but adsorbs molecularly (fixed at a Gibbs Free Energy of $0 \mathrm{eV}$ ). For both the (100) and (001) surfaces, the partial and total dissociation of water have positive free energies and are less stable than water adsorbing molecularly on the surface, in agreement with the experimental results. In contrast, the three configurations are almost isoenergetic for the (101) surface, with the total water dissociation case being the most favorable.

\subsection{Interaction of water with $\mathrm{RuO}_{2}$ under electrochemical conditions}

While the interaction of water vapor with different facets of $\mathrm{RuO}_{2}$ and the energetics of different surface sites for water dissociation can be probed using APXPS, the surface structure under electrochemical conditions remains unknown. We estimate that the $\mathrm{O}_{2} / \mathrm{H}_{2} \mathrm{O}$ equilibrium potential at room temperature for the pressure of water (and background oxygen) in the chamber during APXPS measurements corresponds to a potential of $\sim 0.5$ $0.7 \mathrm{~V}_{\mathrm{RHE}}{ }^{85}$ (calculation shown in Supplementary Information). In order to relate the 
interaction of oriented $\mathrm{RuO}_{2}$ surfaces with water vapor to their surface structure observed in an aqueous environment, we perform surface $\mathrm{X}$-ray scattering measurements on single crystals of (110), (100), (101) and (001) surfaces at 0.5 $\mathrm{V}_{\mathrm{RHE}}$ and $1.0 \mathrm{~V}_{\mathrm{RHE}}$ in $0.1 \mathrm{M} \mathrm{HClO}_{4}$. This allows us to capture the structural changes accompanying the redox transition at $\sim 0.7$

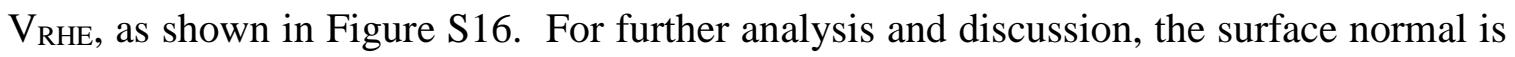
referred to as the (001) direction and the two in-plane directions as the (100) and (010) directions, irrespective of the surface orientations.

The measured intensity (in open circles) for the two potential conditions measured are shown in Figure 3 for the rods that change most drastically as a function of potential, with the remaining rods shown in Figure S21, S26 and S31. Surface structure models for each orientation were created in GenX ${ }^{86}$ (Figure S17, S18, S22, S23, S27, S28). The simulation model consists of distinct layers, and atoms in each layer are subject to fitting constraints. Detailed initial and final atomic positions and constraints are listed in Table S3-S17. In order to verify the experimental findings, DFT computed diagrams showing the most stable structure realized at a given potential were constructed. We note that based on experimental findings, energetics of several adsorption configurations were computed (Table S18-S20), with only the most stable configurations denoted in Figure 4.

Our previous work on the (110) surface ${ }^{79}$ assigned the surface structure at $0.5 \mathrm{~V}_{\mathrm{RHE}}$ to be one where the CUS site was filled with loosely bound water (Rucus-O bond length (2.68 
$\AA$ ), owing to the fitted bond length being significantly larger than the equivalent $\mathrm{Ru}_{\mathrm{bulk}}-\mathrm{O}$ distance of $1.94 \AA$. It is deduced from Figure 3A, that at these low potentials, the bridging oxygen was protonated, with the fitted $\mathrm{Ru}_{\mathrm{BRI}} \mathrm{O} \mathrm{O}$ bond length found to be $2.19 \AA$, significantly larger than previously observed $\mathrm{Ru}_{\mathrm{BRI}} \mathrm{O} \mathrm{O}$ bond lengths $(1.93 \AA$ ) on the stoichiometric surface from previous LEED measurements ${ }^{25}$. A similar structure with water adsorbed on the CUS site with a protonated bridging oxygen was found to be stable at low potentials using $\mathrm{DFT}^{39,79}$. At $1.0 \mathrm{~V}_{\mathrm{RHE}}$, the $\mathrm{Ru}_{\mathrm{CUS}}-\mathrm{O}$ bond distance was found to decrease significantly by $\sim 0.5 \AA$ to $2.19 \AA$ and the RuBRI-O bond length was changed by $\sim 0.24 \AA$ to $1.95 \AA$. The Rucus-O bond length is shorter than the computed Rucus-O bond distance for adsorbed water (2.26 $\AA$ ), but is still significantly longer than the Rucus-O bond distance for an adsorbed oxygen on the CUS site $(1.70 \AA)^{44}$ and the equivalent bulk Ru-O bond length (1.94 $\AA$ ). This, along with our DFT results and previous experimental work suggested that the structure at $1.0 \mathrm{~V}_{\mathrm{RHE}}$ is a stoichiometric surface with every second water molecule on the CUS site dissociated to form -OH on the CUS site with the proton transferred to the neighboring bridging oxygen. As mentioned earlier, the structure realized at 1.0 V $V_{\mathrm{RHE}}$ under aqueous conditions is the same as the predicted "partially dissociated" water structure observed at high water pressure with APXPS. 

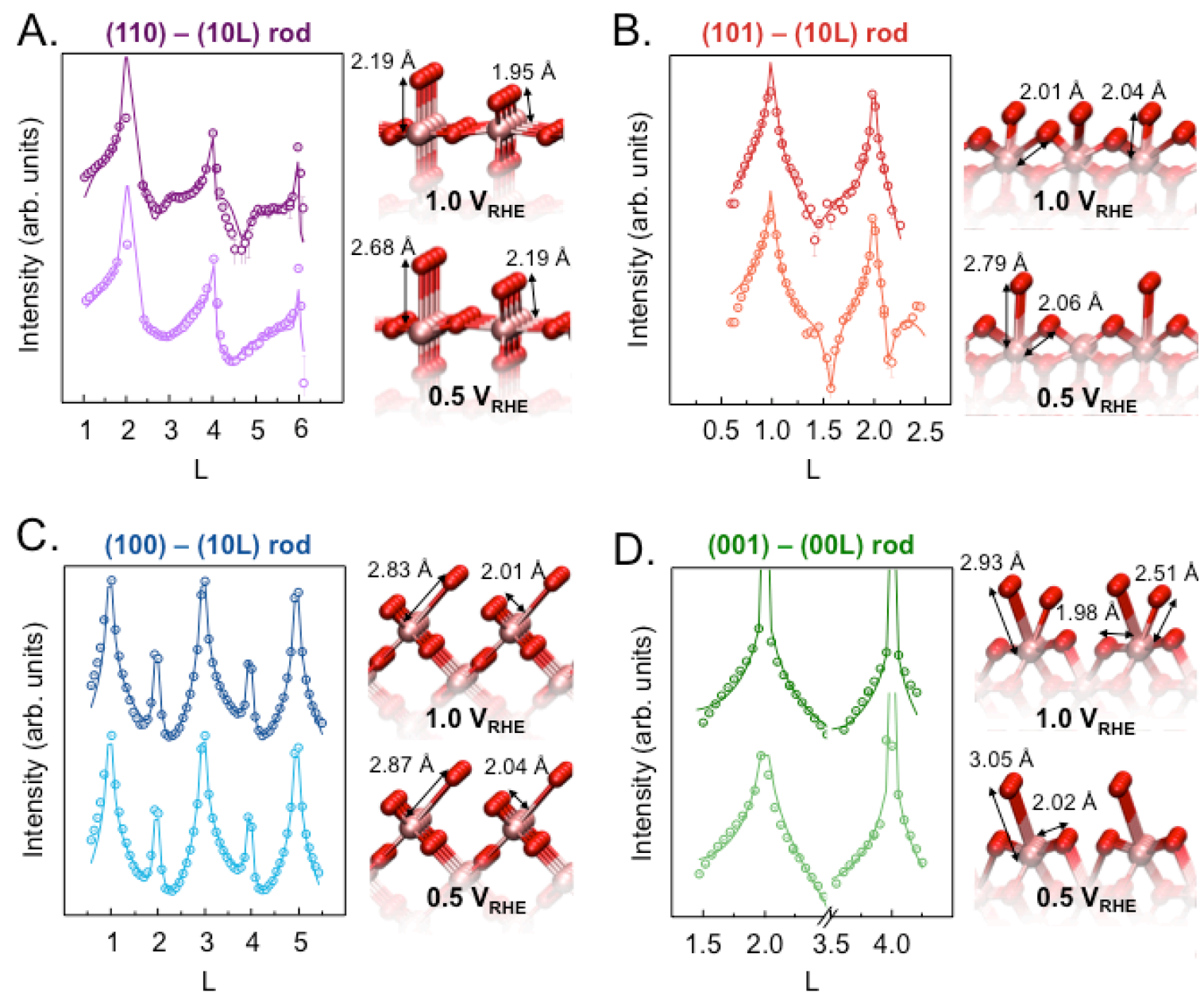

Figure 3: (10L) rods measured at $0.5 \mathrm{~V}_{\mathrm{RHE}}$ (bottom) and $1.0 \mathrm{~V}_{\mathrm{RHE}}$ (top) for the (A) (110) (B) (101) (C) (100) surfaces and (D) the (00L) rod measured at $0.5 \mathrm{~V}_{\mathrm{RHE}}$ and $1.0 \mathrm{~V}_{\mathrm{RHE}}$ for the (001) surface in $0.1 \mathrm{M} \mathrm{HClO}_{4}$. The experimentally measured intensities are shown in open points and the best-fit results from the fitting process are shown in solid lines of the corresponding color. Ball and stick models for the best-fit structures are shown adjacent to the fitted rods. Maximum experimental uncertainty in bond lengths is $0.06 \AA$, with detailed atomic positions found in Tables S3-S17. Pink and red spheres represent $\mathrm{Ru}$ and $\mathrm{O}$ atoms respectively. Bond lengths between surface $\mathrm{Ru}$ and adsorbed $\mathrm{O}$ species are labeled.

We next consider the (101) orientation, which, according to APXPS, was the surface upon which, water dissociation was most facile. The (10L) rod measured at the two potentials shows distinct changes in the anti-Bragg region at $\mathrm{L} \sim 1.5$, in both the position of the minima and the degree of concavity, as seen in Figure 3B. These changes can be reproduced by a simple change in the Rucus-O bond length (Figure S19 and S20). Performing a complete fitting of all rods, results in a surface structure with one loosely 
bound water molecule on every alternate CUS Ru site with a Rucus-O bond length of 2.79 $\AA$, much larger than the $\mathrm{Ru}_{\mathrm{bulk}}-\mathrm{O}$ distance of $1.94 \AA$. The $\mathrm{Ru}_{\mathrm{BRI}}-\mathrm{O}$ bond length on the other hand, was found to be $2.06 \AA$, longer than the RuBRI-O bond distances observed by LEED for a stoichiometric surface $(1.93 \AA)^{25}$, suggesting the presence of a protonated bridging oxygen species at low potentials. DFT results suggested that at low potentials, while the bridge Ru sites were hydroxylated, the CUS sites had an equal occupation of adsorbed $\mathrm{H}_{2} \mathrm{O}$ and -OH groups. While the initial CTR fitting suggests that half the CUS sites were filled with water and the other half were vacant, filling $25 \%$ of the vacant sites with oxygen and a Rucus-O bond length of $2.00 \AA$ does not alter the figure of merit of the fit. Thus, we cannot completely exclude the presence of any -OH on alternate CUS sites. Increasing the potential to $1.0 \mathrm{~V}_{\mathrm{RHE}}$ results in a structure where the $\mathrm{Ru}_{\mathrm{Cus}}-\mathrm{O}$ bond length is dramatically decreased to $2.04 \AA$, while the RuBRI-O is largely unchanged from its value at $0.5 \mathrm{~V}_{\text {RHE}}$. While the Rucus-O bond length is larger than the equivalent bulk Ru-O bond length of 1.94 $\AA$, it is similar to a $\mathrm{Ru}_{\mathrm{CuS}}-\mathrm{O}$ bond length for an -OH group bound to the CUS site from DFT $(2.07 \AA)$ as well as previously computed RuBRI-O bond distance for a protonated bridging oxygen ${ }^{87}$. This suggests that at $1.0 \mathrm{~V}_{\mathrm{RHE}}$, water is completely dissociated to form $-\mathrm{OH}$ on the CUS site with the proton transferred to the adjacent bridging oxygen to form a completely hydroxylated surface.

Having considered the facet where water dissociation was most facile, we next consider the (100) facet, which favored molecular adsorption of water at high water pressures in APXPS. As is evident from Figure 3C, there is no significant difference in the intensity or shape of the anti-Bragg region of the $(10 \mathrm{~L})$ rod, which is otherwise extremely sensitive to changes in Rucus-O bond length, as can be seen in Figure S24. In order to validate that the 
lack of changes observed (10L) rod (and hence the $\mathrm{Ru}_{\mathrm{CUs}}-\mathrm{O}$ bond distance) is not an artifact of poor electrochemistry in the cell, we collect X-ray cyclic voltammograms at $\mathrm{L}=1.65$ and $\mathrm{L}=2.50$ positions. From Figure S24 and S25, it is evident that a decrease in the Rucus bond length increases the intensity at the reciprocal point $\mathrm{L}=2.5$ and decrease the intensity at the reciprocal point $L=1.65$. However, we see that changes at these anti-Bragg conditions are detected only post $1.0 \mathrm{~V}_{\mathrm{RHE}}$, confirming no structural changes associated with the atop oxygen prior to this potential. Fitting the rods collected at $0.5 \mathrm{~V}_{\mathrm{RHE}}$ and 1.0 $\mathrm{V}_{\mathrm{RHE}}$ results in a RuCUS-O bond distance of $2.87 \AA$ and $2.83 \AA$ respectively and a $\mathrm{Ru}_{\mathrm{BRI}} \mathrm{O}$ bond distance of $2.04 \AA$ and $2.01 \AA$ respectively. The $\mathrm{Ru}_{\mathrm{BRI}} \mathrm{O} \mathrm{O}$ bond length is in good agreement with $\mathrm{Ru}_{\mathrm{BRI}} \mathrm{O}$ bond distances probed by LEED on a stoichiometric $\mathrm{RuO}_{2}(100)$ surface, grown by oxidizing a $\mathrm{Ru}(10-10)$ surface, while the Rucus-O is significantly higher than the range of Ru-O bond distances for the (100) surface $(1.90 \AA \text { to } 2.05 \AA)^{55}$. This suggests the presence of a loosely bound water on the CUS site, of an otherwise stoichiometric surface. By probing the nature of the oxygenated adsorbates at the interface, we confirm that the (100) surface has a very low tendency to dissociate water even in an aqueous environment. The similarity of the structures obtained at the two potentials is confirmed by our DFT results, which suggest that at low potentials, the CUS site has an adsorbed water molecule and only every second bridging oxygen is protonated. Increasing the potential to $1.0 \mathrm{~V}_{\mathrm{RHE}}$ results in a structure where all bridging oxygen atoms are deprotonated, with water remaining adsorbed and undissociated on the CUS site. 


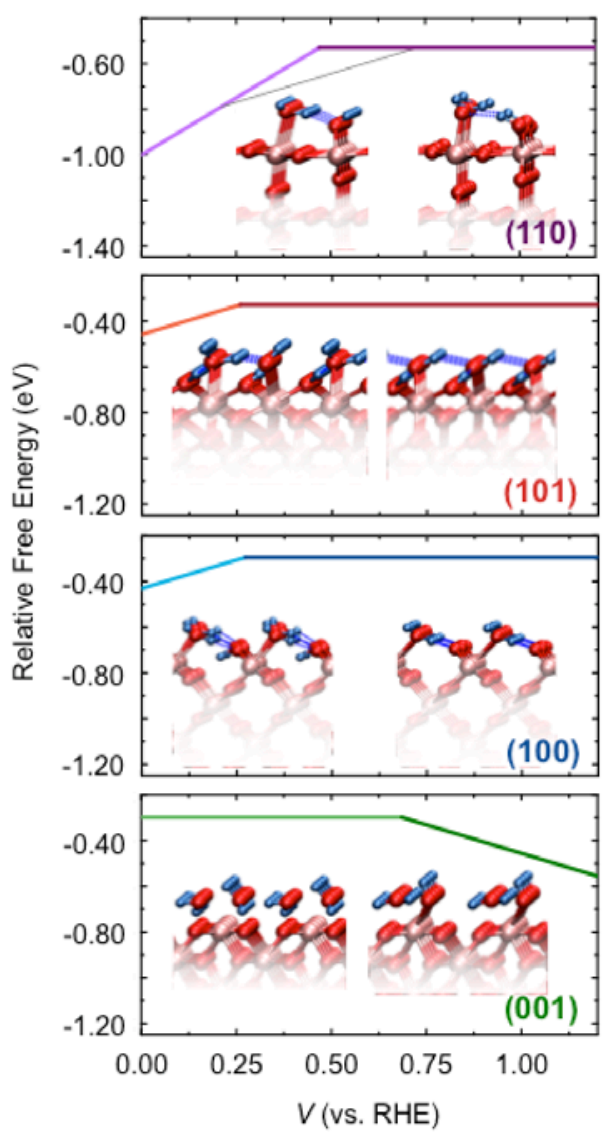

Figure 4: DFT-generated diagram showing the relative Gibbs adsorption energies of the most stable adsorbate configurations as a function of electrochemical potential. The transition from one structure to another is representative of an experimentally observed redox transition at $\sim 0.7 \mathrm{~V}_{\mathrm{RHE}}$ (Fig S16). The horizontal lines indicates the most stable water configuration on the surface. These configurations are similar to those shown in Figure 2C, wherein the (101) surface dissociatively adsorbs water, while the (100) and (001) surfaces molecularly adsorb water and the (110) surface partially dissociates water. For the (110), (101) and (100) surfaces, the stoichiometric surface is stable at higher potentials ( 1.0 $\mathrm{V}_{\mathrm{RHE}}$ ) whereas a more reduced surface, with a water (and $50 \%$ coverage of $-\mathrm{OH}$ for the (101) surface) adsorbed on the CUS site and a (partially) protonated bridging site is observed at lower potentials. In contrast, for the more undercoordinated (001) surface, the stoichiometric surface is only stable at lower potentials, with one of the two adsorbed water molecules dissociating to form an $-\mathrm{OH}$ at high potentials. For the (110) surface, an intermediate state was obtained theoretically, shown in grey, where water was partially dissociated to form $-\mathrm{OH}$ on the CUS site, while the bridging oxygen is protonated. Pink, red and blue spheres represent $\mathrm{Ru}, \mathrm{O}$ and $\mathrm{H}$ atoms respectively. Hydrogen bonds are drawn with blue dashed lines where applicable. The free energies have been referenced to the stoichiometric surface.

Finally, we consider the highly undercoordinated (001) surface where each surface Ru site is only four fold coordinated and can form two "CUS-like" Ru-O bonds on the surface. The intensity at the midzone of the anti-Bragg region could not be measured due to larger 
crystal roughness compared to the other facets. Nevertheless, for this orientation, like the (100) facet, only symmetry changes about the Bragg peak are expected with changing Rucus-O bond distances (Figure S29). The fitted structure at $0.5 \mathrm{~V}_{\mathrm{RHE}}$ corresponds to the Ru being 5-fold coordinated, by filling one out of the possible two binding sites with an oxygen atom. The fitted bond distance is $3.05 \AA$, signifying that this species is probably a loosely bound water molecule. The fitted RuBRI-O bond distance is $2.02 \AA$, which is slightly larger than the $\mathrm{Ru}_{\mathrm{BRI}} \mathrm{O} \mathrm{O}$ bond lengths measured on the (110) surface $(1.93 \AA)^{25}$. Interestingly, unlike the other facets, for the (001) surface, the stoichiometric surface with additional loosely bound water molecule on the CUS site was realized at low potentials (0.5 $\left.\mathrm{V}_{\mathrm{RHE}}\right)$. The highly undercoordinated nature of the surface could explain the higher tendency of surface Ru to be oxidized upon contact with an aqueous solution. Increasing the potential to $1.0 \mathrm{~V}_{\mathrm{RHE}}$ results in a small change in the $(00 \mathrm{~L})$ rod corresponding to the presence of two oxygen atoms with relatively large Rucus-O bond distances of $2.93 \AA$ and $2.51 \AA$ respectively. The bridging oxygen bond distances from Ru remain largely unchanged at $\sim 1.98 \AA$. DFT results suggest that while the structure at low potentials corresponds to a stoichiometric surface with loosely adsorbed water on the surface Ru sites, the increase in potential results in the dissociation of one of the water molecules to form $\mathrm{OH}$. While the CTR results do not show an extreme decrease in the surface $\mathrm{Ru}-\mathrm{O}$ bond distance to justify the presence of only an -OH species on one of the two sites (change in bond length from $3.00 \AA$ to $2.52 \AA$ ), the decrease in bond distance suggests the possibility of some water dissociation.

This study demonstrates the effect of surface crystallographic orientation on the dissociation of water, in the gas-phase environment, as well as in aqueous solutions. These 
observations on well-defined oriented systems can also be extended to nanoparticles, where depending on the oxygen partial pressure and temperature, different particle shapes, exposing unique facets are realized ${ }^{88,89}$; which can interface differently with water. Different facets can stabilize protonated species to a different extent due to the different binding energetics of these species, as well as different degrees of hydrogen bonding. Interestingly, surfaces that are more facile towards water dissociation in the gas phase environment are also capable of dissociating water more easily in the aqueous environment. This trend is in contrast to a recent study on the rutile $\mathrm{TiO}_{2}(110)$ surface that suggested that while in the UHV-like environment, bridging oxygen vacancies reacted with $\mathrm{H}_{2} \mathrm{O}$ to form $-\mathrm{OH}$ species on the bridge Ti sites, the interaction with liquid water was different ${ }^{46}$. In an aerobic aqueous environment, -OH species on the CUS site were stabilized. Similarly, recent studies on strained $\mathrm{SrIrO}_{3}$ films showed good correlation between gas-phase oxygen adsorption and density functional theory calculations, but these trends did not translate to the more complex aqueous electrochemical environment ${ }^{59}$. Our results on the other hand, demonstrate that in spite of the presence of a complex solid-liquid interface, the tendency for water dissociation remains the same in humid atmospheres and in the presence of bulk solution. Furthermore, the lack of any surface reconstruction upon the interaction with water validates its applicability as a model system to study different catalytic processes. This observation also validates the use of gas-phase DFT on these oriented surfaces to model the electrochemical interface. The implications of the differences of water interaction with oriented $\mathrm{RuO}_{2}$ surfaces are far-reaching. Water dissociation is the first step in the oxygen evolution reaction, for which $\mathrm{RuO}_{2}$ is considered to be a highly active. Differences in water dissociation tendency on these surfaces suggest that the difference in 
activities of these surfaces for OER can originate from the different binding energetics for oxygenated intermediates, in addition to differences in active site density. On the other hand, for reactions such as methanol oxidation and hydrochloric acid oxidation, water is the reaction product, and the modification of stability of protonated species at the surface can dramatically influence reaction energetics.

\section{Conclusions}

In this study, we combine different in situ synchrotron techniques as well as theoretical calculations to understand the interaction of oriented $\mathrm{RuO}_{2}$ surfaces with water. $\mathrm{By}$ studying four distinct surface terminations, namely the (110), (100), (101) and (001) surfaces, we highlight the role of surface coordination in the water dissociation ability of these surfaces. The combined use of experimental and theoretical techniques provides unprecedented atomic level insights into the differences in the interaction of water with rutile $\mathrm{RuO}_{2}$ surfaces as a function of crystallographic orientation. Using ambient pressure XPS, the speciation of water under a wide range of relative humidity conditions, from $4.2 * 10^{-5} \%\left(\mathrm{pH}_{2} \mathrm{O}=0.01\right.$ mTorr $)$ to $4.2 \%\left(\mathrm{pH}_{2} \mathrm{O}=1000\right.$ mTorr $)$ was studied. Stark contrasts were observed in the tendency for water dissociation at high relative humidities, with the highest water dissociation for the (101) surface, and lowest for the (100) surface. These studies were complemented by in situ surface diffraction performed on single crystal surfaces as a function of potential. Interestingly, the water dissociation ability under high relative humidity gas-phase conditions is in good agreement with the interaction of liquid water at an electrochemical interface, validating the use of gas-phase DFT to understand the electrochemical interface. This study also confirms the unique role of the two distinct 
sites on the surface, the CUS and bridge sites, in the water activation process. Under the range of experimental conditions studied here $\left(\mathrm{pH}_{2} \mathrm{O}=0.01\right.$ mTorr -1000 mTorr and 0.5 $\left.\mathrm{V}_{\mathrm{RHE}}-1.0 \mathrm{~V}_{\mathrm{RHE}}\right)$, the bridge site is always filled, with the bridging oxygen providing the site for hydrogen adsorption upon water dissociation on the CUS site. Lowering the potential results in the removal of adsorbed -OH groups from the CUS site, while the bridging oxygen site is always present and (partially) protonated under these conditions. The importance of the CUS site for water activation as well as the effect of local coordination on the water dissociation ability for these surfaces provides an additional lever to tune both the density of active sites and the adsorption energetics of key intermediates. This finding can have important ramifications for different (electro)catalytic reactions where water is a reactant (oxygen evolution), product (methanol oxidation, hydrochloric acid oxidation) or a spectator (catalytic reactions in a humid atmosphere). Probing water dissociation at an atomic level provides the first step towards understanding complex processes occurring at the electrochemical interface during water splitting, where questions about the active sites, reaction mechanisms and surface structure remain unknown. The differences in water dissociation tendency observed on different facets opens new avenues to use crystallographic orientation as an additional lever to tune the binding energetics of key intermediates such as $-\mathrm{OH},-\mathrm{O}$, and $-\mathrm{OOH}$.

\section{FIGURE CAPTIONS}

Figure 1: (A) Water isotherm at room temperature $\left(\sim 25^{\circ} \mathrm{C}\right)$ for the $\mathrm{RuO}_{2}(110)$ termination, probing the $\mathrm{O} 1 \mathrm{~s}$ core level at $735 \mathrm{eV}$ incident energy. Spectra are offset for clarity. Spectra are deconvoluted into gas phase water $\left(\mathrm{H}_{2} \mathrm{O}_{\text {vap }}\right)$ shaded in grey, $\mathrm{H}_{2} \mathrm{O}$ and $-\mathrm{OH}$ adsorbed on the CUS site shaded in purple, protonated bridging oxygen in hatched purple and lattice oxygen outlined in black. (B) Intensity of the protonated species on the CUS, either $-\mathrm{OH}$ or $-\mathrm{H}_{2} \mathrm{O}$ (filled) and bridge site (open) normalized to the lattice oxygen peak as a function of water pressure at room temperature. (C) Proposed surface structure at high water pressure showing every second water molecule on the 
CUS site being dissociated, with the hydrogen donated to the neighboring bridging oxygen (Top view shown in Figure S33).

Figure 2: (A) Comparison of the $\mathrm{O} 1 \mathrm{~s}$ spectra measured at a photon energy of $735 \mathrm{eV}$ for the noted orientations. Spectra were measured at room temperature $\left(\sim 25^{\circ} \mathrm{C}\right)$ and a water vapor pressure of 250 mTorr. Spectra are offset for clarity and have been decomposed into the following components - gas phase water outlined in color, protonated species on the CUS site shaded in the corresponding color, protonated species on the BRI site hatched in the same color and lattice oxygen outlined in grey. (B) Intensity of the protonated species on the CUS (filled) and bridge site (open) normalized to the lattice oxygen peak as a function of water pressure at room temperature for the (101) surface (in red) and the (100) surface (in blue). At low partial pressures ( $<50 \mathrm{mTorr}$ ), both orientations adsorb water dissociatively, while at high partial pressures, the (101) surface preferentially adsorbs water dissociatively compared to the (100) surface. (C) Computationally calculated free energy for total (in solid lines) and partially dissociated water (in dashed line) configurations on the stoichiometric surface, for the four different surfaces. The free energy for the two conditions have been referenced to the corresponding stoichiometric surface with a full coverage of water adsorbed on the CUS site, which is shown as a solid grey line at a free energy of $0 \mathrm{eV}$.

Figure 3: (10L) rods measured at $0.5 \mathrm{~V}_{\mathrm{RHE}}$ (bottom) and $1.0 \mathrm{~V}_{\mathrm{RHE}}$ (top) for the (A) (110) (B) (101) (C) (100) surfaces and (D) the (00L) rod measured at $0.5 \mathrm{~V}_{\text {RHE }}$ and $1.0 \mathrm{~V}_{\text {RHE }}$ for the (001) surface in $0.1 \mathrm{M} \mathrm{HClO}_{4}$. The experimentally measured intensities are shown in open points and the best-fit results from the fitting process are shown in solid lines of the corresponding color. Ball and stick models for the best-fit structures are shown adjacent to the fitted rods. Maximum experimental uncertainty in bond lengths is $0.06 \AA$, with detailed atomic positions found in Tables S3-S17. Pink and red spheres represent $\mathrm{Ru}$ and $\mathrm{O}$ atoms respectively. Bond lengths between surface $\mathrm{Ru}$ and adsorbed $\mathrm{O}$ species are labeled.

Figure 4: DFT-generated diagram showing the relative Gibbs adsorption energies of the most stable adsorbate configurations as a function of electrochemical potential. The transition from one structure to another is representative of an experimentally observed redox transition at $\sim 0.7 \mathrm{~V}_{\mathrm{RHE}}$ (Fig S16). The horizontal lines indicates the most stable water configuration on the surface. These configurations are similar to those shown in Figure 2C, wherein the (101) surface dissociatively adsorbs water, while the (100) and (001) surfaces molecularly adsorb water and the (110) surface partially dissociates water. For the (110), (101) and (100) surfaces, the stoichiometric surface is stable at higher potentials ( 1.0 $\left.\mathrm{V}_{\mathrm{RHE}}\right)$ whereas a more reduced surface, with a water (and $50 \%$ coverage of $-\mathrm{OH}$ for the (101) surface) adsorbed on the CUS site and a (partially) protonated bridging site is observed at lower potentials. In contrast, for the more undercoordinated (001) surface, the stoichiometric surface is only stable at lower potentials, with one of the two adsorbed water molecules dissociating to form an $-\mathrm{OH}$ at high potentials. For the (110) surface, an intermediate state was obtained theoretically, shown in grey, where water was partially dissociated to form -OH on the CUS site, while the bridging oxygen is protonated. Pink, red and blue spheres represent $\mathrm{Ru}, \mathrm{O}$ and $\mathrm{H}$ atoms respectively. Hydrogen bonds are drawn with blue dashed lines where applicable. The free energies have been referenced to the stoichiometric surface.

\section{ASSOCIATED CONTENT}

\section{Supporting Information Available:}


Thin film characterization, ambient pressure XPS experimental protocol, Ru3d and O1s fitting parameters and comparison of spectra of different surfaces as a function of water vapor pressure. Electrochemical measurement results of single crystal surfaces in the potential range of $0.4 \mathrm{~V}_{\mathrm{RHE}}$ tp 1.2 $\mathrm{V}_{\text {RHE. }}$. Crystal truncation rod analysis fitting model, sensitivity of fit tests and best-fit results for $0.5 \mathrm{~V}_{\mathrm{RHE}}$ and $1.0 \mathrm{~V}_{\mathrm{RHE}}$ measurements. Energetics for different structures considered using density functional theory. This material is available free of charge via the Internet at http://pubs.acs.org.

\section{AUTHOR INFORMATION}

\section{Corresponding Author}

*Corresponding author. Tel.: +1-617-253-2259 (Y. S.-H.), +1-617-258-0980 (R.R.R.)

E-mail address: shaohorn@mit.edu (Y.S.-H.), reshmar@mit.edu (R.R.R.)

\section{Author Contributions}

The manuscript was written through contributions of all authors. All authors have given approval to the final version of the manuscript.

\section{ACKNOWLEDGMENT}

This work was supported in part by the Skoltech-MIT Center for Electrochemical Energy and the Cooperative Agreement between the Masdar Institute, Abu Dhabi, UAE and the MIT, Cambridge, MA, USA (02/MI/MIT/CP/11/07633/GEN/G/00). The work by H.Y. was supported by U.S. Department of Energy (DOE), Basic Energy Sciences (BES), Materials Sciences and Engineering Division, and the work by H.Z. and the use of the Advanced Photon Source were supported by DOE, BES, Scientific User Facility Division (SUFD), under Contract No. DE-AC02-06CH11357. The work by A.M. was supported by DOE, BES, SUFD under Contract No. DE-AC02-76SF00515. A.F.P. acknowledges the Danish Ministry for Higher Education and Science for an EliteForsk travel grant and the Strategic Research's project NACORR (12-133817). This work used the Extreme Science 
and Engineering Discovery Environment (XSEDE), which is supported by National

Science Foundation grant number ACI-1548562 ${ }^{90}$. This research also used resources of the

National Energy Research Scientific Computing Center, a DOE Office of Science User

Facility supported by the Office of Science of the U.S. Department of Energy under

Contract No. DE-AC02-05CH11231. I.E.L.S acknowledges the Peabody Visiting

Associate Professorship, awarded by the Department of Mechanical Engineering at

Massachusetts Institute of Technology.

\section{References}

(1) Fujishima, A.; Honda, K. Electrochemical Photolysis of Water at a Semiconductor Electrode. Nature 1972, 238, 37.

(2) Henderson, M. A. The Interaction of Water with Solid Surfaces: Fundamental Aspects Revisited. Surf. Sci. Rep. 2002, 46, 1-308.

(3) Thiel, P. A.; Madey, T. E. The Interaction of Water with Solid Surfaces: Fundamental Aspects. Surf. Sci. Rep. 1987, 7, 211-385.

(4) Salmeron, M.; Bluhm, H.; Tatarkhanov, M.; Ketteler, G.; K. Shimizu, T.; Mugarza, A.; Deng, X.; Herranz, T.; Yamamoto, S.; Nilsson, A. Water Growth on Metals and Oxides : Binding, Dissociation and Role of Hydroxyl Groups. Faraday Discuss. 2009, 141, 221-229.

(5) Bergeld, J.; Kasemo, B.; Chakarov, D. V. CO Oxidation on Pt(111) Promoted by Coadsorbed $\mathrm{H}_{2}$ O. Surf. Sci. 2001, 495, L815-L820.

(6) Su, H.-Y.; Yang, M.-M.; Bao, X.-H.; Li, W.-X. The Effect of Water on the CO Oxidation on $\mathrm{Ag}(111)$ and $\mathrm{Au}(111)$ Surfaces: A First-Principle Study. J. Phys. Chem. C 2008, 112, 17303-17310.

(7) Over, H. Surface Chemistry of Ruthenium Dioxide in Heterogeneous Catalysis and Electrocatalysis: From Fundamental to Applied Research. Chem. Rev. 2012, 112, 3356-3426.

(8) Trasatti, S. Electrocatalysis in the Anodic Evolution of Oxygen and Chlorine. Electrochimica Acta 1984, 29, 1503-1512.

(9) Lee, Y.; Suntivich, J.; May, K. J.; Perry, E. E.; Shao-Horn, Y. Synthesis and Activities of Rutile $\mathrm{IrO}_{2}$ and $\mathrm{RuO}_{2}$ Nanoparticles for Oxygen Evolution in Acid and Alkaline Solutions. J. Phys. Chem. Lett. 2012, 3, 399-404.

(10) Stoerzinger, K. A.; Qiao, L.; Biegalski, M. D.; Shao-Horn, Y. OrientationDependent Oxygen Evolution Activities of Rutile $\mathrm{IrO}_{2}$ and $\mathrm{RuO}_{2}$. J. Phys. Chem. Lett. 2014, 5, 1636-1641.

(11) Cherevko, S.; Geiger, S.; Kasian, O.; Kulyk, N.; Grote, J.-P.; Savan, A.; Shrestha, B. R.; Merzlikin, S.; Breitbach, B.; Ludwig, A.; et al. Oxygen and Hydrogen 
Evolution Reactions on $\mathrm{Ru}, \mathrm{RuO}_{2}$, Ir, and $\mathrm{IrO}_{2}$ Thin Film Electrodes in Acidic and Alkaline Electrolytes: A Comparative Study on Activity and Stability. Catal. Today 2016, 262, 170-180.

(12) Danilovic, N.; Subbaraman, R.; Chang, K.-C.; Chang, S. H.; Kang, Y. J.; Snyder, J.; Paulikas, A. P.; Strmcnik, D.; Kim, Y.-T.; Myers, D.; et al. Activity-Stability Trends for the Oxygen Evolution Reaction on Monometallic Oxides in Acidic Environments. J. Phys. Chem. Lett. 2014, 5, 2474-2478.

(13) Paoli, E. A.; Masini, F.; Frydendal, R.; Deiana, D.; Schlaup, C.; Malizia, M.; Hansen, T. W.; Horch, S.; Stephens, I. E. L.; Chorkendorff, I. Oxygen Evolution on Well-Characterized Mass-Selected $\mathrm{Ru}$ and $\mathrm{RuO}_{2}$ Nanoparticles. Chem. Sci. 2014, 6, 190-196.

(14) Gray, H. B. Powering the Planet with Solar Fuel. Nat. Chem. 2009, 1, 7-7.

(15) Walter, M. G.; Warren, E. L.; McKone, J. R.; Boettcher, S. W.; Mi, Q.; Santori, E. A.; Lewis, N. S. Solar Water Splitting Cells. Chem. Rev. 2010, 110, 6446-6473.

(16) Cook, T. R.; Dogutan, D. K.; Reece, S. Y.; Surendranath, Y.; Teets, T. S.; Nocera, D. G. Solar Energy Supply and Storage for the Legacy and Nonlegacy Worlds. Chem. Rev. 2010, 110, 6474-6502.

(17) Kanan, M. W.; Nocera, D. G. In Situ Formation of an Oxygen-Evolving Catalyst in Neutral Water Containing Phosphate and $\mathrm{Co}^{2+}$. Science 2008, 321, 10721075.

(18) Duan, L.; Bozoglian, F.; Mandal, S.; Stewart, B.; Privalov, T.; Llobet, A.; Sun, L. A Molecular Ruthenium Catalyst with Water-Oxidation Activity Comparable to That of Photosystem II. Nat. Chem. 2012, 4, 418-423.

(19) Hisatomi, T.; Kubota, J.; Domen, K. Recent Advances in Semiconductors for Photocatalytic and Photoelectrochemical Water Splitting. Chem. Soc. Rev. 2014, 43, 7520-7535.

(20) Suntivich, J.; May, K. J.; Gasteiger, H. A.; Goodenough, J. B.; Shao-Horn, Y. A Perovskite Oxide Optimized for Oxygen Evolution Catalysis from Molecular Orbital Principles. Science 2011, 334, 1383-1385.

(21) Reier, T.; Nong, H. N.; Teschner, D.; Schlögl, R.; Strasser, P. Electrocatalytic Oxygen Evolution Reaction in Acidic Environments - Reaction Mechanisms and Catalysts. Adv. Energy Mater. 2017, 7, 1601275.

(22) Beer, H. B. The Invention and Industrial Development of Metal Anodes. J. Electrochem. Soc. 1980, 127, 303C-307C.

(23) Trasatti, S. Electrocatalysis: Understanding the Success of DSA®. Electrochimica Acta 2000, 45, 2377-2385.

(24) Sohrabnejad-Eskan, I.; Goryachev, A.; Exner, K. S.; Kibler, L. A.; Hensen, E. J. M.; Hofmann, J. P.; Over, H. Temperature-Dependent Kinetic Studies of the Chlorine Evolution Reaction over $\mathrm{RuO}_{2}$ (110) Model Electrodes. ACS Catal. 2017, 7, 2403-2411.

(25) Over, H.; Kim, Y. D.; Seitsonen, A. P.; Wendt, S.; Lundgren, E.; Schmid, M.; Varga, P.; Morgante, A.; Ertl, G. Atomic-Scale Structure and Catalytic Reactivity of the $\mathrm{RuO}_{2}(110)$ Surface. Science 2000, 287, 1474-1476.

(26) Over, H.; Knapp, M.; Lundgren, E.; Seitsonen, A. P.; Schmid, M.; Varga, P. Visualization of Atomic Processes on Ruthenium Dioxide Using Scanning Tunneling Microscopy. ChemPhysChem 2004, 5, 167-174. 
(27) Kim, Y. D.; Seitsonen, A. P.; Wendt, S.; Wang, J.; Fan, C.; Jacobi, K.; Over, H.; Ertl, G. Characterization of Various Oxygen Species on an Oxide Surface: $\mathrm{RuO}_{2}(110)$. J. Phys. Chem. B 2001, 105, 3752-3758.

(28) Over, H.; Seitsonen, A. P.; Lundgren, E.; Wiklund, M.; Andersen, J. N. Spectroscopic Characterization of Catalytically Active Surface Sites of a Metallic Oxide. Chem. Phys. Lett. 2001, 342, 467-472.

(29) Wang, Y.; Jacobi, K.; Schöne, W.-D.; Ertl, G. Catalytic Oxidation of Ammonia on $\mathrm{RuO}_{2}$ (110) Surfaces: Mechanism and Selectivity. J. Phys. Chem. B 2005, 109, 7883-7893.

(30) Madhavaram, H.; Idriss, H.; Wendt, S.; Kim, Y. D.; Knapp, M.; Over, H.; Aßmann, J.; Löffler, E.; Muhler, M. Oxidation Reactions over $\mathrm{RuO}_{2}$ : A Comparative Study of the Reactivity of the (110) Single Crystal and Polycrystalline Surfaces. J. Catal. 2001, 202, 296-307.

(31) Exner, K. S.; Anton, J.; Jacob, T.; Over, H. Full Kinetics from First Principles of the Chlorine Evolution Reaction over a $\mathrm{RuO}_{2}$ (110) Model Electrode. Angew. Chem. Int. Ed. 2016, 55, 7501-7504.

(32) Crihan, D.; Knapp, M.; Zweidinger, S.; Lundgren, E.; Weststrate, C. J.; Andersen, J. N.; Seitsonen, A. P.; Over, H. Stable Deacon Process for HCl Oxidation over $\mathrm{RuO}_{2}$. Angew. Chem. Int. Ed. 2008, 47, 2131-2134.

(33) Wang, Y.; Jacobi, K.; Ertl, G. Interaction of NO with the Stoichiometric $\mathrm{RuO}_{2}$ (110) Surface. J. Phys. Chem. B 2003, 107, 13918-13924.

(34) Zang, L.; Kisch, H. Room Temperature Oxidation of Carbon Monoxide Catalyzed by Hydrous Ruthenium Dioxide. Angew. Chem. Int. Ed. 2000, 39, 3921-3922.

(35) Sun, Q.; Reuter, K.; Scheffler, M. Hydrogen Adsorption on RuO2(110): DensityFunctional Calculations. Phys. Rev. B 2004, 70, 235402.

(36) Sun, Q.; Reuter, K.; Scheffler, M. Effect of a Humid Environment on the Surface Structure of $\mathrm{RuO}_{2}$ (110). Phys. Rev. B 2003, 67, 205424.

(37) Abbott, D. F.; Mukerjee, S.; Petrykin, V.; Bastl, Z.; Halck, N. B.; Rossmeisl, J.; Krtil, P. Oxygen Reduction on Nanocrystalline Ruthenia - Local Structure Effects. RSC Adv. 2014, 5, 1235-1243.

(38) Rossmeisl, J.; Qu, Z.-W.; Zhu, H.; Kroes, G.-J.; Nørskov, J. K. Electrolysis of Water on Oxide Surfaces. J. Electroanal. Chem. 2007, 607, 83-89.

(39) Watanabe, E.; Rossmeisl, J.; Björketun, M. E.; Ushiyama, H.; Yamashita, K. Atomic-Scale Analysis of the $\mathrm{RuO}_{2} /$ Water Interface under Electrochemical Conditions. J. Phys. Chem. C 2016, 120, 8096-8103.

(40) Lobo, A.; Conrad, H. Interaction of $\mathrm{H} 20$ with the $\mathrm{RuO}_{2}(110)$ Surface Studied by HREELS and TDS. Surf. Sci. 2003, 523, 279-286.

(41) Mu, R.; Cantu, D. C.; Lin, X.; Glezakou, V.-A.; Wang, Z.; Lyubinetsky, I.; Rousseau, R.; Dohnálek, Z. Dimerization Induced Deprotonation of Water on $\mathrm{RuO}_{2}(110)$. J. Phys. Chem. Lett. 2014, 5, 3445-3450.

(42) Reuter, K.; Scheffler, M. Composition, Structure, and Stability of $\mathrm{RuO}_{2}(110)$ as a Function of Oxygen Pressure. Phys. Rev. B 2001, 65, 035406.

(43) Reuter, K.; Scheffler, M. Surface Core-Level Shifts at an Oxygen-Rich Ru Surface: O/Ru(0001) vs. $\mathrm{RuO}_{2}(110)$. Surf. Sci. 2001, 490, 20-28. 
(44) Lindan, P. J. D.; Harrison, N. M.; Gillan, M. J. Mixed Dissociative and Molecular Adsorption of Water on the Rutile (110) Surface. Phys. Rev. Lett. 1998, 80, 762-765.

(45) Hussain, H.; Tocci, G.; Woolcot, T.; Torrelles, X.; Pang, C. L.; Humphrey, D. S.; Yim, C. M.; Grinter, D. C.; Cabailh, G.; Bikondoa, O.; et al. Structure of a Model $\mathrm{TiO}_{2}$ Photocatalytic Interface. Nat. Mater. 2017, 16, 461.

(46) Pang, C. L.; Lindsay, R.; Thornton, G. Chemical Reactions on Rutile $\mathrm{TiO}_{2}$ (110). Chem. Soc. Rev. 2008, 37, 2328-2353.

(47) Bikondoa, O.; Pang, C. L.; Ithnin, R.; Muryn, C. A.; Onishi, H.; Thornton, G. Direct Visualization of Defect-Mediated Dissociation of Water on $\mathrm{TiO}_{2}$ (110). Nat. Mater. 2006, 5, 189-192.

(48) Mu, R.; Cantu, D. C.; Glezakou, V.-A.; Lyubinetsky, I.; Rousseau, R.; Dohnálek, Z. Deprotonated Water Dimers: The Building Blocks of Segmented Water Chains on Rutile $\mathrm{RuO}_{2}$ (110). J. Phys. Chem. C 2015, 119, 23552-23558.

(49) Giordano, L.; Goniakowski, J.; Suzanne, J. Partial Dissociation of Water Molecules in the (3x2) Water Monolayer Deposited on the Mg0 (100) Surface. Phys. Rev. Lett. 1998, 81, 1271-1273.

(50) Kim, Y. D.; Lynden-Bell, R. M.; Alavi, A.; Stulz, J.; Goodman, D. W. Evidence for Partial Dissociation of Water on Flat MgO(100) Surfaces. Chem. Phys. Lett. 2002, 352, 318-322.

(51) Meyer, B.; Marx, D.; Dulub, O.; Diebold, U.; Kunat, M.; Langenberg, D.; Wöll, C. Partial Dissociation of Water Leads to Stable Superstructures on the Surface of Zinc Oxide. Angew. Chem. Int. Ed. 2004, 43, 6641-6645.

(52) Wang, Y.; Muhler, M.; Wöll, C. Spectroscopic Evidence for the Partial Dissociation of $\mathrm{H}_{2} \mathrm{O}$ on $\mathrm{ZnO}(10-10)$. Phys. Chem. Chem. Phys. 2006, 8, 15211524.

(53) Mulakaluri, N.; Pentcheva, R.; Wieland, M.; Moritz, W.; Scheffler, M. Partial Dissociation of Water on $\mathrm{Fe}_{3} \mathrm{O}_{4}(001)$ : Adsorbate Induced Charge and Orbital Order. Phys. Rev. Lett. 2009, 103, 176102.

(54) Kim, Y. D.; Schwegmann, S.; Seitsonen, A. P.; Over, H. Epitaxial Growth of Ru02(100) on Ru(10-10): Surface Structure and Other Properties. J. Phys. Chem. B 2001, 105, 2205-2211.

(55) Kim, Y. D.; Over, H.; Krabbes, G.; Ertl, G. Identification of $\mathrm{RuO}_{2}$ as the Active Phase in CO Oxidation on Oxygen-Rich Ruthenium Surfaces. Top. Catal. 2000, 14, 95-100.

(56) Kavathekar, R. S.; Dev, P.; English, N. J.; MacElroy, J. M. D. Molecular Dynamics Study of Water in Contact with the $\mathrm{TiO}_{2}$ Rutile-110, 100, 101, 001 and Anatase-101, 001 Surface. Mol. Phys. 2011, 109, 1649-1656.

(57) Henderson, M. A. Structural Sensitivity in the Dissociation of Water on $\mathrm{TiO}_{2}$ Single-Crystal Surfaces. Langmuir 1996, 12, 5093-5098.

(58) Kuo, D.-Y.; Eom, C. J.; Kawasaki, J. K.; Petretto, G.; Nelson, J. N.; Hautier, G.; Crumlin, E. J.; Shen, K. M.; Schlom, D. G.; Suntivich, J. Influence of Strain on the Surface-Oxygen Interaction and the Oxygen Evolution Reaction of SrIrO3. J. Phys. Chem. C 2018, 122, 4359-4364. 
(59) Lister, T. E.; Chu, Y.; Cullen, W.; You, H.; Yonco, R. M.; Mitchell, J. F.; Nagy, Z. Electrochemical and X-Ray Scattering Study of Well Defined $\mathrm{RuO}_{2}$ Single Crystal Surfaces. J. Electroanal. Chem. 2002, 524-525, 201-218.

(60) Lister, T. E.; Tolmachev, Y. V.; Chu, Y.; Cullen, W. G.; You, H.; Yonco, R.; Nagy, Z. Cathodic Activation of $\mathrm{RuO}_{2}$ Single Crystal Surfaces for Hydrogen-Evolution Reaction. J. Electroanal. Chem. 2003, 554-555, 71-76.

(61) Petach, T. A.; Mehta, A.; Marks, R.; Johnson, B.; Toney, M. F.; Goldhaber-Gordon, D. Voltage-Controlled Interfacial Layering in an Ionic Liquid on $\mathrm{SrTiO}_{3} . A C S$ Nano 2016, 10, 4565-4569.

(62) Kresse, G.; Hafner, J. Ab Initio Molecular Dynamics for Liquid Metals. Phys. Rev. $B$ 1993, 47, 558-561.

(63) Kresse, G.; Furthmüller, J. Efficient Iterative Schemes for Ab Initio TotalEnergy Calculations Using a Plane-Wave Basis Set. Phys. Rev. B 1996, 54, 11169-11186.

(64) Perdew, J. P.; Burke, K.; Ernzerhof, M. Generalized Gradient Approximation Made Simple. Phys. Rev. Lett. 1996, 77, 3865-3868.

(65) Blöchl, P. E. Projector Augmented-Wave Method. Phys. Rev. B 1994, 50 , 17953-17979.

(66) Kresse, G.; Joubert, D. From Ultrasoft Pseudopotentials to the Projector Augmented-Wave Method. Phys. Rev. B 1999, 59, 1758-1775.

(67) Monkhorst, H. J.; Pack, J. D. Special Points for Brillouin-Zone Integrations. Phys. Rev. B 1976, 13, 5188-5192.

(68) Loffreda, D. Theoretical Insight of Adsorption Thermodynamics of Multifunctional Molecules on Metal Surfaces. Surf. Sci. 2006, 600, 2103-2112.

(69) Chase, M.W; Davies, C.A; Downey, J.R; Frurip, D.J; McDonald, R.A; Syverud, A.N. Eds; NIST-JANAF Thermochemical Tables, American Institute of Physics, 3rd edn, J. Phys. Chem. Ref. Data, 1985, vol. 14 (Suppl. 1).

(70) Nørskov, J. K.; Rossmeisl, J.; Logadottir, A.; Lindqvist, L.; Kitchin, J. R.; Bligaard, T.; Jónsson, H. Origin of the Overpotential for Oxygen Reduction at a Fuel-Cell Cathode. J. Phys. Chem. B 2004, 108, 17886-17892.

(71) Martínez, J. I.; Hansen, H. A.; Rossmeisl, J.; Nørskov, J. K. Formation Energies of Rutile Metal Dioxides Using Density Functional Theory. Phys. Rev. B 2009, 79, 045120.

(72) Kolb, M. J.; Calle-Vallejo, F.; Juurlink, L. B. F.; Koper, M. T. M. Density Functional Theory Study of Adsorption of $\mathrm{H}_{2} \mathrm{O}, \mathrm{H}, \mathrm{O}$, and $\mathrm{OH}$ on Stepped Platinum Surfaces. J. Chem. Phys. 2014, 140, 134708.

(73) Ketteler, G.; Yamamoto, S.; Bluhm, H.; Andersson, K.; Starr, D. E.; Ogletree, D. F.; Ogasawara, H.; Nilsson, A.; Salmeron, M. The Nature of Water Nucleation Sites on $\mathrm{TiO}_{2}(110)$ Surfaces Revealed by Ambient Pressure X-Ray Photoelectron Spectroscopy. J. Phys. Chem. C 2007, 111, 8278-8282.

(74) Newberg, J. T.; Starr, D. E.; Yamamoto, S.; Kaya, S.; Kendelewicz, T.; Mysak, E. R.; Porsgaard, S.; Salmeron, M. B.; Brown, G. E.; Nilsson, A.; et al. Formation of Hydroxyl and Water Layers on MgO Films Studied with Ambient Pressure XPS. Surf. Sci. 2011, 605, 89-94.

(75) Blume, R.; Hävecker, M.; Zafeiratos, S.; Teschner, D.; Knop-Gericke, A.; Schlögl, R.; Dudin, P.; Barinov, A.; Kiskinova, M. Oxidation of Methanol on Ru Catalyst: 
Effect of the Reagents Partial Pressures on the Catalyst Oxidation State and Selectivity. Catal. Today 2007, 124, 71-79.

(76) Wang, L.-Q.; Baer, D. R.; Engelhard, M. H.; Shultz, A. N. The Adsorption of Liquid and Vapor Water on $\mathrm{TiO}_{2}$ (110) Surfaces: The Role of Defects. Surf. Sci. 1995, 344, 237-250.

(77) Hugenschmidt, M. B.; Gamble, L.; Campbell, C. T. The Interaction of $\mathrm{H}_{2} \mathrm{O}$ with a $\mathrm{TiO}_{2}$ (110) Surface. Surf. Sci. 1994, 302, 329-340.

(78) Wang, Y.; Lafosse, A.; Jacobi, K. Adsorption and Reaction of $\mathrm{CO}_{2}$ on the $\mathrm{RuO}_{2}$ (110) Surface. J. Phys. Chem. B 2002, 106, 5476-5482.

(79) Rao, R. R.; Kolb, M. J.; Halck, N. B.; Pedersen, A. F.; Mehta, A.; You, H.; Stoerzinger, K. A.; Feng, Z.; Hansen, H. A.; Zhou, H.; et al. Towards Identifying the Active Sites on $\mathrm{RuO}_{2}(110)$ in Catalyzing Oxygen Evolution. Energy Environ. Sci. 2017, 10, 2626-2637.

(80) Stoerzinger, K. A.; Rao, R. R.; Wang, X. R.; Hong, W. T.; Rouleau, C. M.; ShaoHorn, Y. The Role of Ru Redox in pH-Dependent Oxygen Evolution on Rutile Ruthenium Dioxide Surfaces. Chem 2017, 2, 668-675.

(81) Stoerzinger, K. A.; Diaz-Morales, O.; Kolb, M.; Rao, R. R.; Frydendal, R.; Qiao, L.; Wang, X. R.; Halck, N. B.; Rossmeisl, J.; Hansen, H. A.; et al. OrientationDependent Oxygen Evolution on $\mathrm{RuO}_{2}$ without Lattice Exchange. ACS Energy Lett. 2017, 2, 876-881.

(82) Axnanda, S.; Scheele, M.; Crumlin, E.; Mao, B.; Chang, R.; Rani, S.; Faiz, M.; Wang, S.; Alivisatos, A. P.; Liu, Z. Direct Work Function Measurement by Gas Phase Photoelectron Spectroscopy and Its Application on PbS Nanoparticles. Nano Lett. 2013, 13, 6176-6182.

(83) Feng, Z. A.; Balaji Gopal, C.; Ye, X.; Guan, Z.; Jeong, B.; Crumlin, E.; Chueh, W. C. Origin of Overpotential-Dependent Surface Dipole at $\mathrm{CeO}_{2-x} /$ Gas Interface During Electrochemical Oxygen Insertion Reactions. Chem. Mater. 2016, 28, 6233-6242.

(84) Stoerzinger, K. A.; Pearce, C. I.; Droubay, T. C.; Shutthanandan, V.; Shavorskiy, A.; Bluhm, H.; Rosso, K. M. Impact of Ti Incorporation on Hydroxylation and Wetting of $\mathrm{Fe}_{3} \mathrm{O}_{4}$. J. Phys. Chem. C 2017, 121, 19288-19295.

(85) Stoerzinger, K. A.; Hong, W. T.; Wang, X. R.; Rao, R. R.; Bengaluru Subramanyam, S.; Li, C.; Ariando; Venkatesan, T.; Liu, Q.; Crumlin, E. J.; et al. Decreasing the Hydroxylation Affinity of $\mathrm{La}_{1-\mathrm{X}} \mathrm{Sr}_{\mathrm{x}} \mathrm{MnO}_{3}$ Perovskites To Promote Oxygen Reduction Electrocatalysis. Chem. Mater. 2017, 29, 99909997.

(86) Björck, M.; Andersson, G. GenX: An Extensible X-Ray Reflectivity Refinement Program Utilizing Differential Evolution. J. Appl. Crystallogr. 2007, 40, 11741178.

(87) Wang, J.; Fan, C. Y.; Sun, Q.; Reuter, K.; Jacobi, K.; Scheffler, M.; Ertl, G. Surface Coordination Chemistry: Dihydrogen versus Hydride Complexes on $\mathrm{RuO}_{2}$ (110). Angew. Chem. Int. Ed. 2003, 42, 2151-2154.

(88) Wang, T.; Jelic, J.; Rosenthal, D.; Reuter, K. Exploring PretreatmentMorphology Relationships: Ab Initio Wulff Construction for $\mathrm{RuO}_{2}$ Nanoparticles under Oxidising Conditions. ChemCatChem 2013, 5, 33983403. 
(89) Wang, T.; Reuter, K. Structure Sensitivity in Oxide Catalysis: First-Principles Kinetic Monte Carlo Simulations for $\mathrm{CO}$ Oxidation at $\mathrm{RuO}_{2}$ (111). J. Chem. Phys. 2015, 143, 204702.

(90) Towns, J.; Cockerill, T.; Dahan, M.; Foster, I.; Gaither, K.; Grimshaw, A.; Hazlewood, V.; Lathrop, S.; Lifka, D.; Peterson, G. D.; et al. XSEDE: Accelerating Scientific Discovery. Comput. Sci. Eng. 2014, 16, 62-74. 
$\underline{\text { TOC Graphic }}$
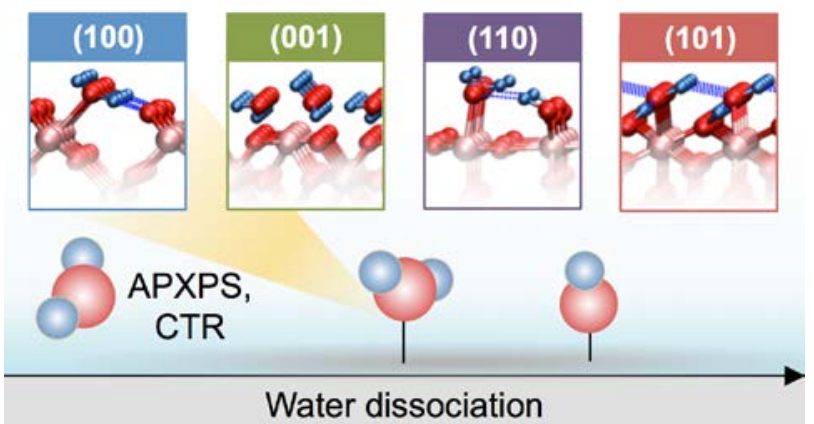

Water dissociation 